\title{
Determination of Total Volatile Organic Compounds in Recycled Plastic by Headspace/Gas Chromatography-Mass Spectrometry
}

\author{
ShanhaoXu ${ }^{1}$, ChuanLuo $^{1}$, HaoWang ${ }^{2}$, YinZhang ${ }^{3}$, ChaoZhang ${ }^{3}$ and LifengYuan ${ }^{2 *}$ \\ ${ }^{1}$ Ningbo Customs District, QinYi Road 66\#, NingBo, 315012, P. R. China \\ ${ }^{2}$ Ningbo academy of science and technology for inspection and quarantine, QinYi Road 66\#, NingBo, 315012, P. R. China \\ ${ }^{3}$ Joysun Testing service, QinYi Road 66\#, NingBo, 315012, P.R. China
}

\begin{abstract}
A method of headspace combination with gas chromatography-mass spectrometry was developed for the determination of total volatile organic compounds (TVOC) from recycled plastic. The factors such as equilibrium temperature, equilibrium time and sample uniformity were investigated. Toluene was selected as reference material. The results showed that the optimum conditions were as follows: equilibrium temperature was $80^{\circ} \mathrm{Cand}$ equilibrium time was $25 \mathrm{~min}$. The calibration curves showed good linearity and the correlative coefficients was 0.9975 . The method detection $\operatorname{limit}(\mathrm{S} / \mathrm{N}=3)$ was $0.01 \mathrm{mg} / \mathrm{kg}$, and the recoveries ranged from $83.5 \%$ to $108.3 \%$, with RSDs $<6 \%$. The method has the advantages of no pretreatment, accurate results and high sensitivity etc., and can be used for the determination of TVOC from recycled plastic.
\end{abstract}

\section{Introduction}

Volatile organic compounds (VOCs) refer to organic compounds that are prone to volatilize at room temperature, including alkanes, alkenes, aromatics, halogenated hydrocarbons, alcohols, aldehydes, ketones and so on. TVOC is a term used to represent the pool of volatile organic compounds. Some volatile halogenated compounds are toxic to human body even at low concentration ${ }^{[1]}$, and some VOCs that are hard to degrade can cause bioaccumulation effect, affecting biological system and environment on a large scale ${ }^{[2]}$. Therefore, there are strict control standards and policies for TVOC emission at home and abroad ${ }^{[3]}$. At present, the detection of VOCs is performed mainly via gas chromatography [4], thermal analysis/ gas chromatography-mass spectrometry [5], headspace-gas chromatography ${ }^{[6]}$.

Recycled plastics generally contain VOCs because of their complex sources, incomplete cleaning, as well as cracking and decomposition during processing. With the ban on imported solid waste and tightening environmental protection policies, higher demands have been proposed for the quality of recycled plastics ${ }^{[7,8]}$. At present, there have been few reports on the detecting methods of VOCs in recycled plastics. The headspace sample (HS) combined with gas chromatography-mass spectrometry (GC-MS) is developed in recent years to detect volatile substances, which was free from tedious pretreatment, interference of solvent impurities and less pollution. This technology has the characteristics of avoiding tedious pretreatment, avoiding interference of solvent impurities, and reducing pollution to the injection port and chromatographic column.

This paper tested TVOC in recycled plastics via headspace-gas chromatography-mass spectrometry that skipped pretreatment and featured high accuracy and sensitivity.

\section{Experimental part}

\subsection{Instruments and conditions}

Instrument: Gas chromatography-mass spectrometry, GC2030-QP2020NX from SHIMADZU of Japan, with EI source; Headspace sampler: AOC-6000 from SHIMADZU of Japan; Analytical balance, METTLER TOLEDO from TOLEDO of Switzerland, with a sensitivity of $0.1 \mathrm{mg} ; 22 \mathrm{~mL}$ headspace bottle; $10 u \mathrm{~L}$ microinjector.

\subsection{Reagents and materials}

Helium, purity $\geq 99.999 \%$; Methanol (HPLC grade from TEDIA of USA); Toluene standard solution (99.7\%, Dr.Ehrenstorfer of Germany);Preparation of standard stock solution of toluene $(1 \mathrm{mg} / \mathrm{mL})$ : $0.1 \mathrm{~g}$ of toluene standard was weighed and adjusted to $100 \mathrm{~mL}$ with methanol;

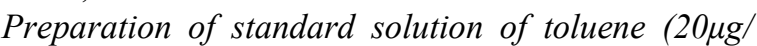
$\mathrm{mL}$ ): $1.0 \mathrm{~mL}$ standard stock solution of toluene was removed and adjusted to $50 \mathrm{~mL}$ with methanol. 


\subsection{Methods and conditions}

\subsubsection{Gas chromatography-mass spectrometry conditions}

Chromatographic column: DB-624,60 $\mathrm{m} \times 0.25 \mathrm{~mm} \times$ $1.40 \mu \mathrm{m}$; Temperature: inlet at $250^{\circ} \mathrm{C}$, auxiliary heating zone at $250{ }^{\circ} \mathrm{C}$, ion source at $200^{\circ} \mathrm{C}$. Keep the state for $4 \mathrm{~min}$ before rising to $200{ }^{\circ} \mathrm{C}$ at the rate of $6^{\circ} \mathrm{C} / \mathrm{min}$, and stay at the temperature for $5 \mathrm{~min}$. Next, rise to $240{ }^{\circ} \mathrm{C}$ at the rate of $20^{\circ} \mathrm{C} / \mathrm{min}$ and stay there for Imin. Split sampling in the ratio of 10:1; Carrier gas: Helium at the flow rate of $1.0 \mathrm{~mL} / \mathrm{min}$. Ionization: EI (70 ev); Quality scanning: 35 amu-350 amu; Solvent delay: 4min; Scanning mode: Full scan (SCAN).

\subsubsection{Headspace conditions:}

Balance point temperature: $80{ }^{\circ} \mathrm{C}$; Duration: $25 \mathrm{~min}$; Temperature of sampling needle: $80^{\circ} \mathrm{C}$.

\subsubsection{Procedure}

$0.5 \mathrm{~g}$ of sample (to an accuracy of $0.1 \mathrm{mg}$ ) was weighed, placed in the headspace bottles and sealded instantly for analysis via headspace gas chromatography mass spectrometry.

\section{Results and discussions}

\subsection{Selection of markers}

TVOC refers to any organic compound whose boiling point or initial boiling point is lower than or equal to $250{ }^{\circ} \mathrm{C}$ at the standard atmospheric pressure. The National Standard GB 18581-2009 Limits of Harmful Substances in Solvent-based Woodware Coatings for Interior Decoration Materials defines diethyl adipate (boiling point of $251{ }^{\circ} \mathrm{C}$ ) as a marker. That is, classify substances released before the marker as VOC and those after the marker as non-VOC. The sum of substances released before the marker adds up to the total volatile organic compounds (TVOC).

This paper followed the above standard and defined the diethyl adipate (boiling point of $251^{\circ} \mathrm{C}$ ) as a marker, and the sum of substances before the marker as TVOC.

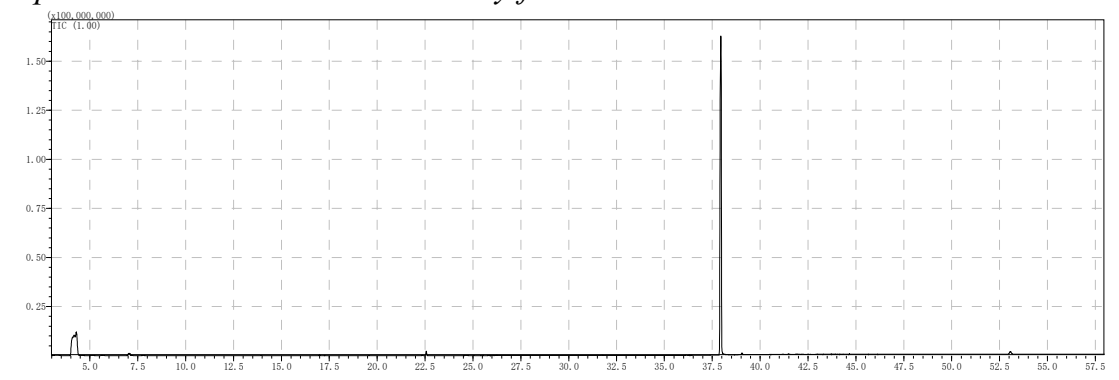

Fig.1 Total ion chromatogram of Diethyl Adipate

\subsection{Calculation of TVOC}

it is almost impossible to calculate TVOC by accurately quantifying VOCs in all recycled plastics.

There are various kinds of compounds in TVOC, which vary with materials, sources and procedures. Therefore,

Table1 VOCs of different kinds of samples

\begin{tabular}{ccc}
\hline No. & Sample type & TVOC \\
\hline 1 & PE & Acetic acid, Decane, Limonene \\
2 & PP & Hexadecane, Nonylene, Toluene, Nonane \\
3 & PA & Aniline, Toluene, Styrene \\
4 & PC & Dichloromethane, Phenol, Styrene, Xylene, Toluene \\
5 & ABS & Styrene, Acrylonitrile, Toluene \\
6 & PS & Dodecane, Trichloroethylene, Styrene, Benzophenone \\
7 & PVC & Hexadecane, Isooctanol, Heptanone \\
8 & PET & Dodecane, Benzothiazole, Toluene \\
\hline
\end{tabular}

Based on GB 18581-2009 Limits of Harmful Substances in Solvent-based Wood Coatings for Interior Decoration Materials, this paper set the response factor of all VOC substances relative to toluene at 1.0. That is, all VOC substances were regarded as toluene.

\subsection{Selection of equilibrium temperature}

Volatile organic compound refers to organic compound that is volatile at room temperature, whose concentration in air is closely related to temperature. Generally, the higher the temperature, the higher the concentration. Given the fact that the temperature of recycled plastics 
peaks at about $60{ }^{\circ} \mathrm{C}$ in routine transportation, storage and use, this paper set the equilibrium temperature at $80^{\circ} \mathrm{C}$ after taking into account analyzing methods of volatile organic compounds in other plastic products ${ }^{[9,10]}$.

\subsection{Determining balancing duration}

This paper investigated the effects of balancing duration of $5,10,15,20,25$ and $30 \mathrm{~min}$ on the analysis results, which showed that the concentration of VOCs in gas phase increased with the extension of equilibrium time. As the sample was in equilibrium at $25 \mathrm{~min}$, this paper set the parameter at $25 \mathrm{~min}$ for time efficiency.

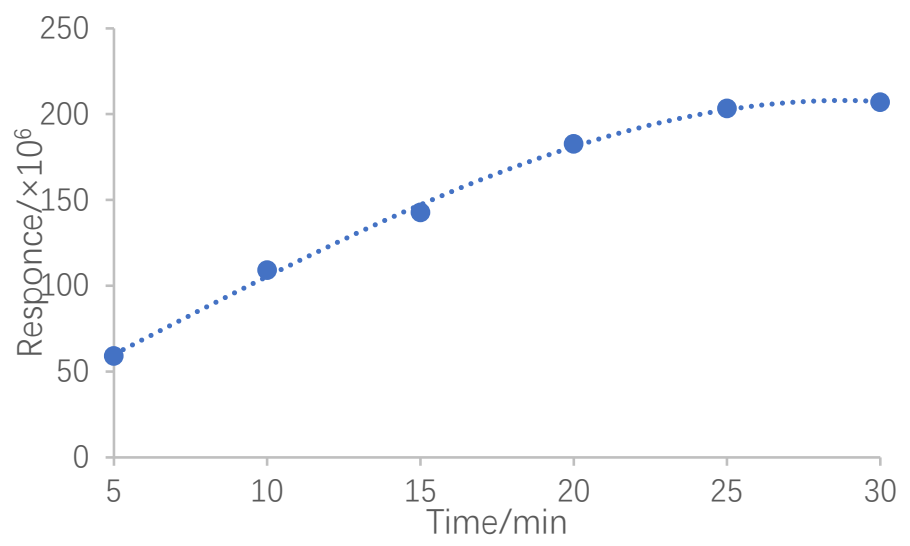

Fig.2 Effects of different equilibrium times

\subsection{Investigation of sample homogeneity}

Generally, recycled plastic particles are not homogeneous because of their complex sources and components. Therefore, it is necessary to investigate their homogeneity. This paper selected a sample of about $2 \mathrm{~kg}$. After mixing evenly, 8 segments were selected from different parts of the sample to test the proportion of volatile organic compounds via full scanning. This paper also investigated the relative standard deviations of 6 highly-concentrated volatile organic compounds. The results (Table 2) showed that the relative standard deviations of 6 substances were all less than 5\%, featuring good uniformity.

Table 2 The results of the homogeneity testing $(n=8)$

\begin{tabular}{cccc}
\hline No. & compound & retention time $/$ min & RSD $(\%)$ \\
\hline 1 & Hexane & 9.365 & 1.7 \\
2 & Benzene & 12.490 & 2.1 \\
3 & Toluene & 16.980 & 3.0 \\
4 & Ethylbenzene & 20.865 & 4.9 \\
5 & P-xylene & 21.155 & 4.1 \\
6 & Isopropyl benzene & 23.200 & 4.6
\end{tabular}

\subsection{Linear relationship and detection limit}

Add 1.0, 2.0, 5.0, 10, 20, 50, and $100 \mu \mathrm{L}$ toluene standard solution into seven headspace bottles, seal the bottles immediately and analyze them in descending order of concentration. The peak surface of total ion flow relative to the concentration of toluene was used to obtain the curve of total volatile organic compounds (Figure 3), with a linear correlation coefficient of 0.9975 . Also, the detection limit was determined at $0.01 \mathrm{mg} / \mathrm{kg}$ (MLOD, $\mathrm{S} / \mathrm{N}=3$ ). 


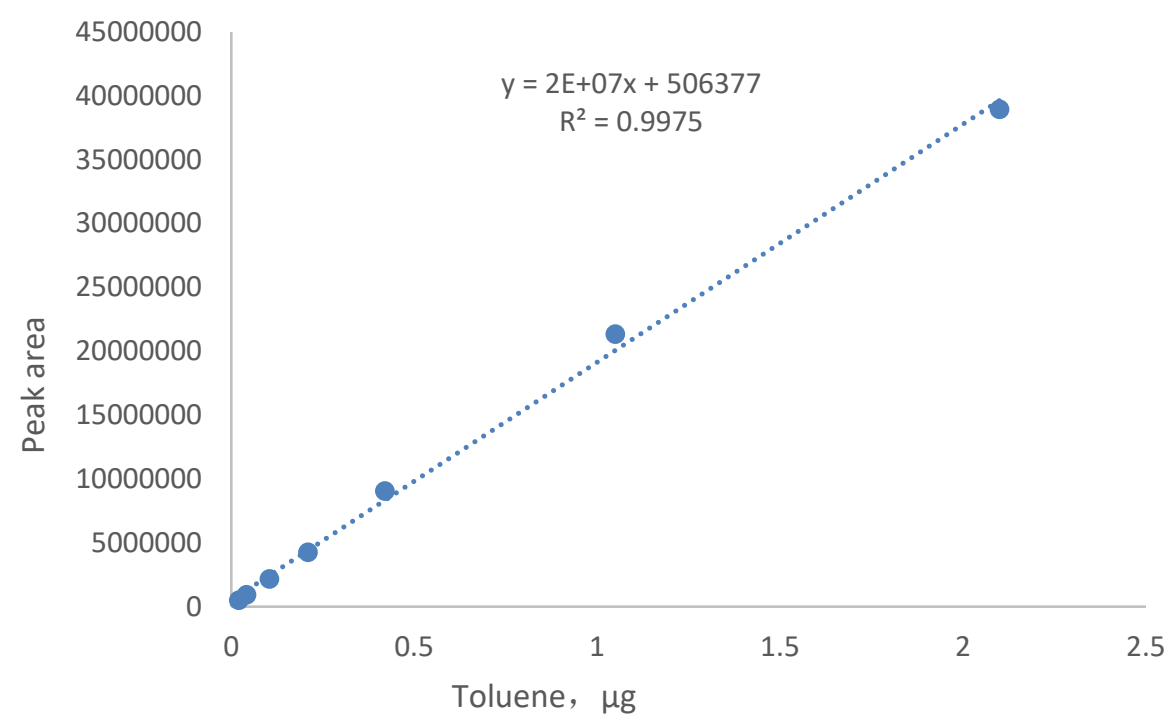

Fig.3 Linear equation of TVOC

\subsection{The recovery rate and precision of the method}

One PP and one PVC regenerated particle sample were selected for six parallel experiments and standard recovery experiments, the results of which are shown in
Table 3. It showed that the relative standard deviation (RSD) of TVOC was less than $6 \%$, with an average recovery rate of $83.5 \%-108.3 \%$ in the range of standard addition. The method features high recovery and precision.

Table 3 Determination results of recoveries and precisions $(n=6)$

\begin{tabular}{ccccc}
\hline No. & Sample & RSD $(\%)$ & Spiked $(\mathrm{mg} / \mathrm{kg})$ & Recovery(\%) \\
\hline 1 & PP & 5.62 & $0.2,2$ & $89.2,108.3$ \\
2 & PVC & 3.99 & $0.2,2$ & $83.5,99.8$ \\
\hline
\end{tabular}

\subsection{Testing of actual samples}

Two samples of ABS, PA, PC, PE, PET, PP, PS and PVC were selected and tested using this method. The results are shown in Table 4.

Table4 The results of the samples

\begin{tabular}{ccc}
\hline No. & Sample type & TVOC $(\mathrm{mg} / \mathrm{kg})$ \\
\hline 1 & ABS & $0.30,1.21$ \\
2 & PA & $0.56,0.12$ \\
3 & PC & $2.7,0.30$ \\
4 & PE & $7.83,2.13$ \\
5 & PET & $<0.01,0.14$ \\
6 & PP & $7.01,3.91$ \\
7 & PS & $3.75,0.66$ \\
8 & PVC & $8.82,3.30$ \\
\hline
\end{tabular}

\section{Conclusion}

This paper used headspace-gas chromatography-mass spectrometry to determine TVOC in recycled plastics, with a lower limit of $0.01 \mathrm{mg} / \mathrm{kg}$, a recovery rate between $83.5 \%$ and $108.3 \%$, and a repeatability of less than $6 \%$. The method requires no pretreatment and features accurate results and high sensitivity.

\section{Acknowledgements}

This work was financially supported by the science research project of General Administration of Customs, P. R. CHINA (Fund No.: 2019HK016), the Ningbo public science research project (Fund No.: 2019C50031) and the Zhejiang basis public science research project (Fund No.: LGC20B040001).

\section{References}

1. Spyros K G, Themistokles D L, Anastasia D N. (2001) Comparison of methods for determination of volatile organic compounds in drinking water. Chemosphere, 45: 275-284

2. Safarova V I, Sapelnikova S V, Djazhenko E V, . etc. (2004) Gas chromatography-mass spectrometry with headspace for the analysis of volatile organic compounds in waste water. J.Chromatogr. B, 800: 325-330

3. KE FY, CHEN Y, HU JY. etc. (2019) Formation mechanism and control technology on volatile organic compounds of regenerated polyester fiber. China Synthetic Fiber Industry, 42(1):49-54

4. International Organization for Standardization. (2013) Paints and varnishes - Determination of 
volatile organic compound (VOC) content - Part 2: Gas-chromatographic method: ISO 11890-22013.Published in Switzerland.

5. International Organization for Standardization. (2011) Indoor air - Part 6: Determination of volatile organic compounds in indoor and test chamber air by active sampling on Tenax TA sorbent, thermal desorption and gas chromatography using MS or MS-FID: ISO 16000-6-2011. Published in Switzerland.

6. International Organization for Standardization. (2005) Paints and varnishes - Determination of the volatile organic compound content of low-VOC emulsion paints (in-can VOC): ISO 17895:2005. Published in Switzerland.

7. Luo C., Wang H., Wang Q., etc. (2020) Application of Instrumental in the Identification of Solid Waste Characteristic of Imported recycled ABS Plastic. Earth. Environ.Sci., 508(2020)012205

8. Luo C, Dai SJ, Zhang Y., etc. (2021) Identification Method of Solid Waste Characteristic for Imported Recycled Engineering Plastics. Earth Environ. Sci. 621(2021)012050

9. GUO XD, CHEN YG, ZHANG PL. etc. (2018) Research on Volatile Organic Compounds in Six Types of Plastic Products. Contemporary Chemical Industry, 47(4):809-813

10. JIANG BL, WU XY, XIONG GL. etc. (2019) Research of VOC and Odor of Polyurethane Foams. Polyurethane Industry, 34:20-23 